\title{
Arijo: Location-Specific Data Crowdsourcing Web Application as a Curriculum Supplement
}

\author{
Justin Banusing, Cedrick Jason Cruz, Peter John Flores, Eisen Ed Briones, Gerald Salazar, Rhydd Balinas, Serafin \\ Farinas \\ Philippine Science High School - Western Visayas \\ Iloilo City, Philippines
}

\begin{abstract}
Smart devices are quickly becoming more accessible to the general public. With the proper tools, they can be used to supplement the work of educators. According to studies by Beeland Jr. and Roussou, learning through interaction has been considered to be effective by both students and teachers. This study aimed to develop an interactive curriculum supplement for smart devices in the form of a Location-specific Data Crowdsourcing Web Application (Arijo) which teaches students how to conduct experiments and upload their results to the internet for archival purposes. Arijo was developed with a combination of the Appsheet framework, Adobe Photoshop, and Google Maps. Three core functionalities were programmed: data input/output, data interpretation, and information dissemination. Arijo was able to perform its intended features, such as recording and displaying data within specific locations, along with displaying guides on how to conduct an experiment. Arijo was able to fulfill its main objective, to be a curriculum supplement, through the aforementioned features. In the future, Arijo may be expanded to support more year levels and multiple curriculums because of its modular nature.
\end{abstract}

Keywords-Web application; smart devices; data crowdsourcing; curriculum supplement

\section{INTRODUCTION}

Science, Technology, Engineering and Math or STEM, is an educational discipline focusing on the four aforementioned fields. Apart from promoting and exposing students to those fields, teaching STEM has been shown to have a positive impact on both students and educators alike. This includes teaching the efficiency and inquiry skills required to succeed in STEM-related endeavors [1].

A study by Estonanto [2] showed that there was a low acceptability of the new Philippine STEM curriculum among stakeholders. It revealed that the major problems were on the areas of the Facility and Instructional Materials, and the difficulty of coursework. He concluded that there was much to be improved about existing learning materials.

New ways can be added to the area of the Facility and Instructional Materials to promote STEM, one of which is interactive learning. There exist studies that prove that interactive learning benefits both students and teachers. Beeland Jr. [3] studied the effects of interactive whiteboards in classrooms, the purpose of which was to determine how student engagement was affected by using interactive tools throughout the learning process. The results showed that the aforementioned tool resonated with learners and lecturers alike while also increasing student engagement.

Nowadays, the technology present in the interactive whiteboards of old can be found in everyday smart devices such as phones, laptops, and tablets. Smart devices are hardware that possess the ability to perform "ubiquitous computing", which gives them the ability to run complex programs known as applications. These programs have multiple uses, one of which is data input and output. Using sensors commonly found in contemporary smart devices, some applications can find location-specific data such as GPS coordinates and ambient air temperature. Using the internet, some applications are able to disseminate information like news, weather forecasts and stock market statistics.

Other applications even involve data crowdsourcing, the act of gathering data from the public. Data gathered via crowdsourcing is valuable for researchers, businesses, and the public alike, as they can help predict trends and identify potential solutions to problems. Location-specific data are among these, it being information related to a specific locale. An example of an application that primarily makes use of crowdsourced location-specific data is Waze, which uses traffic information sourced from public repositories to determine optimal travel routes.

However, with the existence of multiple smart devices and platforms of differing specifications to develop for, the feasibility of developing a platform-specific native application is low when faced with limited time and resources.

This is why an alternative exists in the form of the web application. Utilizing a user's web browser to run the program from a remote source, little to no data is tied to the device itself. Web applications have the same functionality as their offline counterpart but have the ability to work across different platforms so as long as there is internet access. Examples of popular web applications are Yahoo and Google's mail clients [4].

There are a number of ways to develop web applications. Just like native applications, they can be developed using tools such as application programming interfaces (API) and frameworks. These tools vary in complexity, difficulty and capability [5]. Appsheet is one such framework. It is designed to allow developers to create spreadsheet-based web applications for the primary purpose of data crowdsourcing. 
Using Appsheet and data crowdsourcing, Arijo (based on the Hiligaynon phrase "Ari oh", which means "here it is") was programmed to be an application that will supplement the STEM discipline by integrating smart devices into activities already done with the current Philippines curriculum.

\section{REVIEW OF LITERATURE}

\section{A. Learning through Interactive Content}

Several studies have proven that interactive learning is highly preferred by students and teachers. One such study by Beeland Jr [3] measured students' engagement when their teachers used interactive whiteboards. The study's purpose was to determine the effect of the use of interactive whiteboards to see if the student engagement in the learning process increases while using the interactive whiteboard as an instructional tool. The majority of participating students and teachers indicated that they had a strong preference for the use of the interactive whiteboards in classrooms.

Roussou [6] developed an interactive, participatory, and multi-sensory environment where the combination of physical and virtual realities made for a more exciting learning experience for children. Those who tested her free flowing, interactive learning environment were found to have an increased interest in learning. Roussou stated that her tests turned out the way they did because learners in an activity gain their knowledge by testing ideas and concepts based on their stock knowledge and experience and applying them to new situations, something that interactive environments encourage.

\section{B. Smart Devices}

Smart devices are a form of hardware defined as having the ability to perform "ubiquitous computing". These include smartphones, personal computers, tablet computers, wearable computers and the like. The definition encompasses devices that have certain components. First are the power components, the devices' power sources. Second are the memory components that give devices the ability to read and write data. Third are the processing components, allowing devices to execute operations. Lastly, communication interfaces embedded within enable them to communicate with other devices of varying distance [7].

\section{Appsheet}

Appsheet is an application programing interface (API) that allows users to create hybrid applications on both Android and iOS devices. The API creates form based applications and allows users to store the data to Google Drive, Dropbox, Smartsheet, OneDrive, Microsoft Office, Box, and SQL Server. It also allows users to utilize different phone functions such as GPS, camera, barcode reader, and signature capture.

\section{Web Application}

Web applications are applications invoked through an internet connection. Within a decade since its mass adoption in 1994, the Web has evolved from a repository of pages for static information into a platform capable of application development and deployment. Creating dynamic applications with the help of new Web technologies, languages, and methodologies represent a new model of cooperation and collaboration among large number of users. Web application development quickly adopts software engineering techniques of component orientation and standard components. For instance, search, syndication, and tagging have become standard components for the new generation of collaborative applications and processes.

Web application development in the future will be driven by browser technology advances, Web infrastructure, protocol standards, software engineering methods, and application trends [8].

\section{E. Use of Smart Devices as Data Gathering Tools}

There is an approach in data gathering called participatory sensing where the data is collected by the users and sent through their mobile smart devices. With the increasing commonality of mobile smart devices, such an approach has become viable. Participatory sensing as a concept utilizes a mobile smart device's GPS, camera, microphone, clock, magnetic sensors and other features to collect and send data [9]. However, not all smartphones have the required apparatus to collect complex forms of data; as such, external apparatus is needed in certain cases.

With the rise of the number of people using smartphones today, it is a great to use this opportunity to promote STEM to people and students.

\section{F. Related Studies}

The GLOBE Project similarly crowdsources scientific data through use of a web-based form for personal computers and a web application for mobile smart devices. It allows students, teachers and the general public to participate in data collection at predefined and verified points of interest such as schools. [10].

Epicollect is a similar data crowdsourcing application that collects data, scientific and otherwise, from users. Instead of having pre-defined data types however, all data entries are self-defined and associated with a user-made repository [11].

\section{1) Comparison of Similar Studies}

Arijo is similar to the other applications at the base level (see Table I). Just like the GLOBE Project and Epicollect, it is to be a data crowdsourcing application.

Arijo, however, is not meant to be a competitor to the applications above; its purpose is entirely different. However, similar to the GLOBE Project, Arijo uses GPS to assign usersubmitted data to the appropriate location. They share several function and types of data. Arijo's differences however, lie in two areas: account verification and data collection. While the GLOBE Project requires prospective data collectors to have verified accounts (endorsed by the school) and restricts them to pre-defined data collecting sites, Arijo is to maintain a freefor-all system so as to avoid entry barriers and increase the possible user base. However, Arijo features verification in the form of teacher/supervisor codes. 
TABLE I. COMPARISON OF ARIJO TO SIMILAR APPLICATIONS.

\begin{tabular}{|l|l|l|l|}
\hline Feature & Arijo & GLOBE Project & Epicollect \\
\hline Mobile Application & $\checkmark$ & $\checkmark$ & $\checkmark$ \\
\hline Automatic GPS Location & $\checkmark$ & $\checkmark$ & $\checkmark$ \\
\hline Device Clock & $\checkmark$ & $\checkmark$ & $\checkmark$ \\
\hline Open Source Spreadsheet & $\checkmark$ & $\checkmark$ & $\checkmark$ \\
\hline Device Camera & $\checkmark$ & $\checkmark$ & $\checkmark$ \\
\hline Online Maps Integration & $\checkmark$ & $\checkmark$ & \\
\hline PC Accessibility & $\checkmark$ & $\checkmark$ & $\checkmark$ \\
\hline Requires Verification & $\checkmark$ & $\checkmark$ & \\
\hline Self-defined Data Collecting Sites & $\checkmark$ & & \\
\hline Pre-defined Types of Data & $\checkmark$ & $\checkmark$ & \\
\hline
\end{tabular}

Epicollect shares a number of features with both the Arijo and the GLOBE Project but serves as a repository for userdefined data that fall under user-defined data types. Rather than having pre-defined types of data, it allows users to do so. As such, nothing is specific and everything must be handled on a case-per-case basis. Arijo is to be similar to it in that it allows users to define their own data gathering points and gather data but unlike it allows data gathering in any point and is not limited to predefined data collection sites.

\section{G. Elements of an Accessible User Interface}

When designing an application's user interface, there are techniques and patterns to be followed in order for it to be accessible [12].

\section{1) Clarity}

Clarity is the most important element of user interface design. The purpose of user interface design is to enable people to interact with the system by communicating meaning and function. If people cannot figure out how the application works, it will confuse people and will fail as a user interface.

\section{2) Concision}

Clarity in a user interface is important. However, one must not over-clarify. The developer needs to be aware of the size of the interface. An excessive amount of explanations will cost users more time in order to go through them.

\section{3) Familiarity}

Making a user interface familiar is making it appear to look like something that people have encountered before, sparing the users the time to find out how it works.

\section{4) Responsiveness}

Making a user interface responsive means making it fast enough that users will not have to wait too long for a response. Animations are a part of an interface's responsiveness.
5) Consistency

Consistency is the similarity in appearance of different parts of an application. Making a user interface consistent makes it easier for users to navigate the application.

\section{6) Attractiveness}

Attractiveness is making the application look pleasing. But one must not overdo the attractiveness of an interface for it can make it less pleasing instead. Attractiveness increases the appeal of the application.

\section{7) Clarity}

An application's efficiency makes it easier and friendlier to the users. An efficient application is one that performs tasks in the fastest and shortest way possible.

\section{8) Forgiving}

A forgiving application is one that makes the users redo tasks when executed wrong. A great example of an application's forgivingness is the undo feature that lets the user redo the task that was performed.

\section{H. Parameters Related to the Philippine School Curriculum}

The data types and experiments supported by Arijo were based on the Philippine Department of Education's curriculum guide for grades three, four, and five science subjects (see Table II). There are learning objectives to be accomplished at the end of each grade level according to the aforementioned guide, all of which are satisfied by the data types and experiments supported by Arijo [13].

TABLE II. TABLE Showing The Three Year LeVEls' Associated DATA TYPES

\begin{tabular}{|c|c|}
\hline Year Level & Data Types \\
\hline Grade 3 & $\begin{array}{l}\text { Types of Water (Salt Water, Fresh Water) } \\
\text { Salinity }\end{array}$ \\
\hline Grade 4 & $\begin{array}{ll}- & \text { Water Parameters (Temperature, Acidity) } \\
\text { - } & \text { Soil Type } \\
\text { - } & \text { Dissolved Oxygen } \\
& \text { Weather (Cloud Type) } \\
\end{array}$ \\
\hline Grade 5 & - Rock Type \\
\hline
\end{tabular}

\section{1) Grade 3}

According to the DepEd, learners should be able to describe the functions of the different parts of their environment by the end of grade 3 , specifically water. Arijo's first featured data type in the grade 3 level is water type, which is part of that year level's goal of teaching students how to classify matter within the first quarter grading period.

\section{a) Water Types}

Freshwater is water that is collected from freshwater bodies such as lakes, rivers, falls and others. Lakes, rivers, and wetlands are examples of bodies of freshwater [14].

Saltwater is water that is collected from the sea and ocean. They are known for having a salinity of 35,000 ppt and higher.

\section{2) Grade 4}

By the end of grade 4, DepEd states that learners should be able to investigate the observable changing properties of materials when mixed with other materials or when there is an 
applied force to it. Learners should be able to classify the different types of soil and which is best for certain plants and infer the importance of water in daily activities. Learners should also apply their knowledge of what makes up the weather and weather conditions.

Arijo's featured data types in the grade 4 level are water temperature, water acidity, dissolved oxygen in water, weather, soil type, and cloud type. These data types are part of that year level's fourth quarter grading period, where learners are taught about the importance of water, soil and weather parameters.

\section{a) Water Parameters Affecting Plants}

Temperature is the amount or intensity of heat present in a substance or object. Monitoring temperature is important because it influences water chemistry. The rate of chemical reactions generally increases at higher temperature. Water with higher temperatures can dissolve more minerals from rocks and will therefore have a higher electrical conductivity. It is the opposite when considering a gas, such as oxygen, dissolved in water. Water temperature is measured using a thermometer [15].

Acidity or $\mathrm{pH}$ is the measurement on how acidic or basic water is. It is the number of free hydrogen $(\mathrm{H})$ and hydroxyl $(-\mathrm{OH})$ in the water. It is measured by using a water parameter sensor, using reagents or litmus paper.

Dissolved oxygen is the level of free, non-compound oxygen present in water. It is measured by using modern dissolved oxygen sensors, colorimetric method, or titration [16].

\section{b) Types of Clouds}

Clouds are formed by tiny ice crystals. There are four basic types of clouds. They are: cirrus, cumulus, nimbus, and stratus. They usually represent the incoming weather of a certain place.

\section{c) Soil Investigation}

Soil investigation is investigating and observing of the soil to know important details about the soil.

Soil type is the general classification of soil depending on its consistency, location, color and other factors. The type of soil can affect what plants can grow in an area as well as how plants grow in an area. Soil type is identified by referring to a guide and comparing the characteristics of a soil sample to established archetypes. Examples of soil types are loam, clay, silt and sand

\section{3) Grade 5}

By the end of the 5th grade, students under the DepEd curriculum are expected to be able to infer that properties of materials may form new materials due to certain conditions. Arijo's featured data type in the grade 5 level is rock type, the determination of which is part of that year level's 4th quarter activities on changes to the earth [13].

\section{a) Rock Types}

Main rock types that are commonly used as basis for identification are these three types namely igneous, metamorphic, and sedimentary. These types may only be found in specific locations and possess unique characteristics; as such, can help scientists determine the nature of a location.

\section{METHODOLOGY}

This study aimed to develop a Location-specific Data Crowdsourcing Web Application (Arijo) using Appsheet as an API and Google Sheets as the data repository.

When developing software, the programmer must ensure that all of an application's components work correctly. In order to do so, the development of the web application was divided into multiple phases.

Starting from a barebones data input and output application, features were added phase-by-phase. At the end of each phase, a form of evaluation was done to determine if the implementation of new features was successful (see Fig. 1).

Arijo's data flow and operation was aimed to be straightforward. Once a user begins the data submission process, the system simply follows the program flow (see Fig. 2)

\section{A. Materials}

- Personal Computer

- Internet Access

- Android OS Mobile Phone

- Apple iOS Mobile Phone

- Appsheet Account

- Google Account

- Google Sheets

\section{B. Diagrams}

\section{1) Timeline of Developmental Phases}

Development was done in phases (see Fig. 1) with evaluation done after each phase.

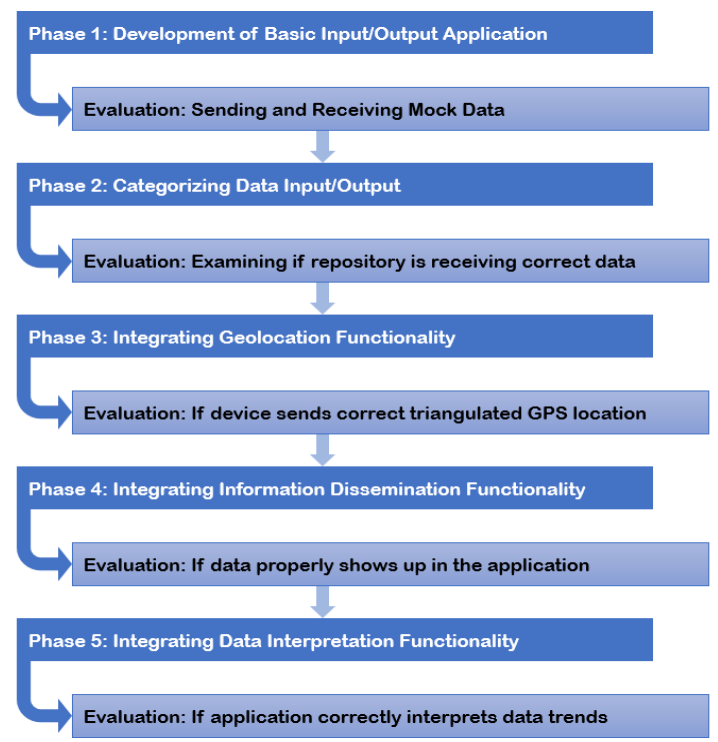

Fig. 1. Timeline of developmental phases for Arijo. 
2) Application Operation Flowchart

The flowchart (see Fig. 2) shows Arijo's operation and data flow.

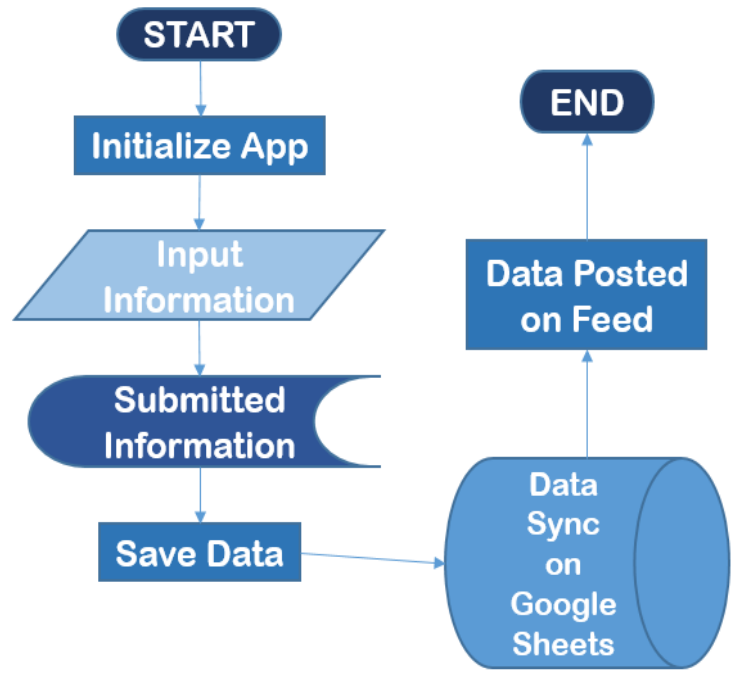

Fig. 2. Application operation flowchart of Arijo.

\section{Procedures}

\section{1) User Interface Design}

User interface is a key concept when developing an application. Regardless of an application's function, its user interface must follow a set of standards in order to be accessible. Before beginning work on Arijo proper, a user interface following such standards was designed so as to streamline development by providing a mockup of what the final product would look like (see Fig. 3).
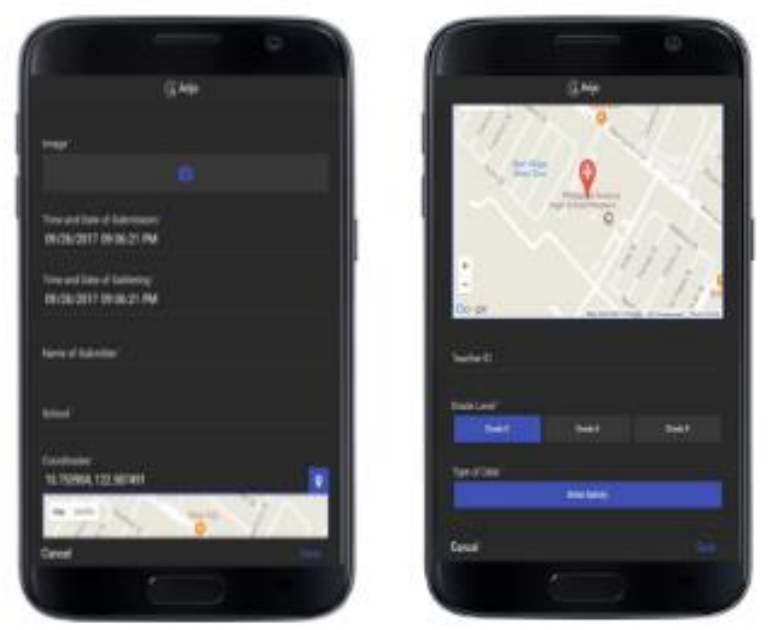

Fig. 3. Mock-up of the input (worksheet) page's user interface.

\section{2) Development} Application

a) Phase 1 - Development of a Basic Input/Output

Arijo's initial phase was a basic input/output web application using the Appsheet API. It was developed to send data from a user's device to the destination data repository, a Google Sheet (see Fig. 4 and 5).

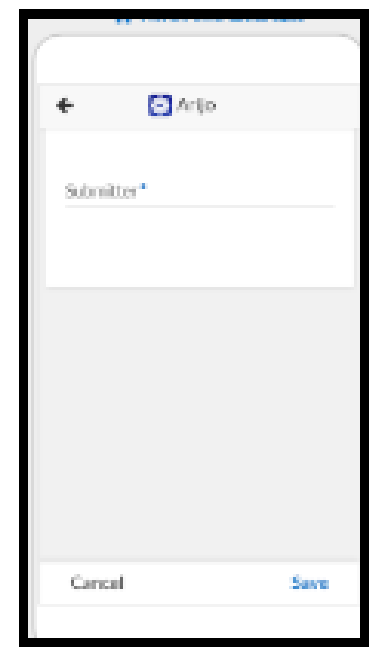

Fig. 4. Input portion of Arijo

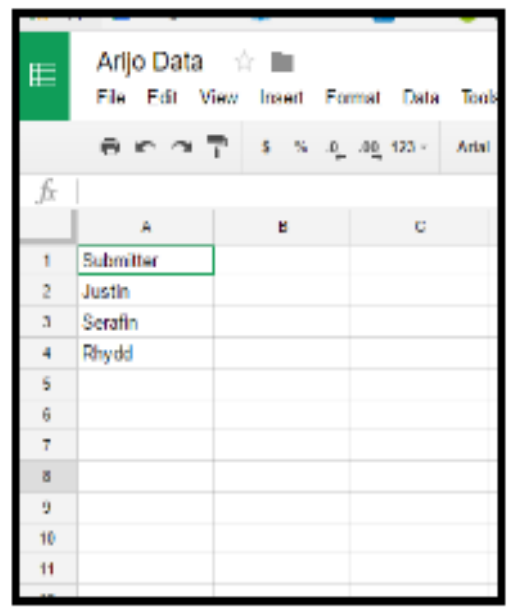

Fig. 5. Output portion of Arijo.

\section{b) Phase 2 - Categorizing Data Input/Output}

The second phase of Arijo's development was about presenting the data gathering procedures and categorizing data input and output.

Phase 1's basic input/output web application was overhauled to introduce selectors and input fields for the data to be collected as well as other important details like photographs and the submitter's name. These new forms were programmed by adding new fields to the Google Sheet and reconstructing the database in Appsheet. As a result, submitted inputs on the data fields are received by the Google Sheet.

User experience behavior was programmed so that data types can only be selected if a previous data field contained a specific input. When a grade level is selected, the only data types able to be chosen for entry are those associated with said grade level. After a data type is selected, it will be the only field present; all other data types will not appear (see Fig. 6 and 7). 


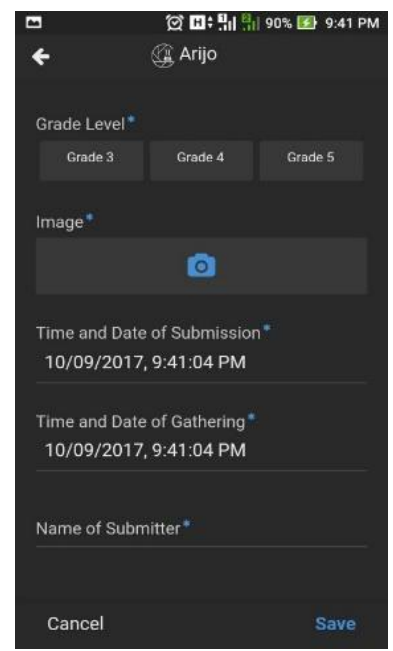

Fig. 6. A portion of the finalized input screen.

\begin{tabular}{|c|c|c|c|c|c|c|c|c|c|}
\hline & A & B & c & D & $\mathrm{E}$ & $\mathrm{F}$ & G & H & I \\
\hline 1 & Image & Time and Date $\alpha$ & Ie and Date & a Name of Submitt & ttSchool & Coordinates & Teacher ID & Grade Level & Type of Data \\
\hline 2 & Arijo Data_Image & 1/115/2017 & 1/15/2017 & 7 Justin Banusing & PSHS-WVC & $10.315699,123$ & ENA & Grade 5 & Rock Type \\
\hline 3 & Arijo Data_Image & 1/17/2017 & 1/117/2017 & 7 Rhyod Jay Balin: & niPSHS-WVC & $10.315699,123$ & ¿NA & Grade 4 & Soll Type \\
\hline 4 & Arijo Data_Image & 2/111/2017 & 2/11/2017 & 7 Serafin Farinas & PSHS-WVC & $10.315699,123$ & ENA & Grade 3 & Water Type \\
\hline 5 & Arijo Data_Image & 2/111/2017 & 2/11/2017 & 7 Serafín Farinas & PSHS-WVC & $10.315699,123$ & 3. ¿NA & Grade 4 & Water Temperath \\
\hline 6 & Arijo Data_Image & 2/111/2017 & 2/11/2017 & 7 Serafín Farinas & PSHS-WVC & $10.315699,123$ & B. 2 NA & Grade 4 & Water Aciodty \\
\hline 7 & Arijo Data_Image & 2/111/2017 & 2/11/2017 & 7 Serafin Farinas & PSHS-WVC & $10.315699,123$ & B. NNA & Grade 4 & Dissolved Oxyg \\
\hline 8 & Arijo Data_Image & 2/111/2017 & 2/11/2017 & 7 Serafin Farinas & PSHS-WVC & 10.315699, 123 & B.. NA & Grade 4 & Weather \\
\hline 9 & Arijo Data_Image & 3/7/2017 & 37/2017 & 7 Serafin Farinas & PSHS-WVC & $14.041000,15.4$ & 4. NA & Grade 3 & Water Salinity \\
\hline 10 & Arijo Data_Image & $3 / 72017$ & 377/2017 & 7 Serafin Farinas & PSHS-WVVC & $10.753634,122$ & 2:NA & Grade 5 & Rock Type \\
\hline 11 & Arili Data Image & 4/16/2017 & 4/16/2017 & 7 Farinas & PSHS-WVC & $10.753327,122$ & 2:NA & Grade 5 & Rock Type \\
\hline
\end{tabular}

Fig. 7. A portion of the finalized output screen.

\section{c) Phase 3 - Integrating Geolocation Functionality}

In Arijo's third phase, geolocation or the ability to detect a user's location was added. Appsheet's GPS module was enabled, thus allowing the web application to interface with a phone's GPS sensor when queried by the input form. Arijo is able to automatically add GPS coordinates to a user's data submission, though a user can manually select the location should they be submitting data retroactively (see Fig. 8).

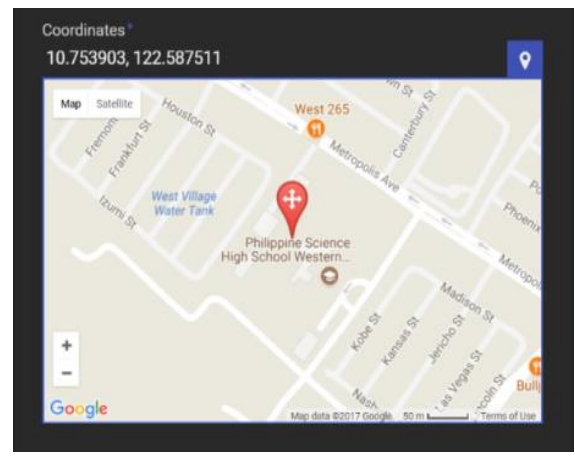

Fig. 8. Coordinate input are of Arijo.

Using Appsheet's Maps view module, which itself is powered by Google Maps, a new portion was added to the web application wherein the submitted GPS coordinates will be shown as points on the world map. This creates create a graphic representation of where data was submitted from (see Fig. 9).

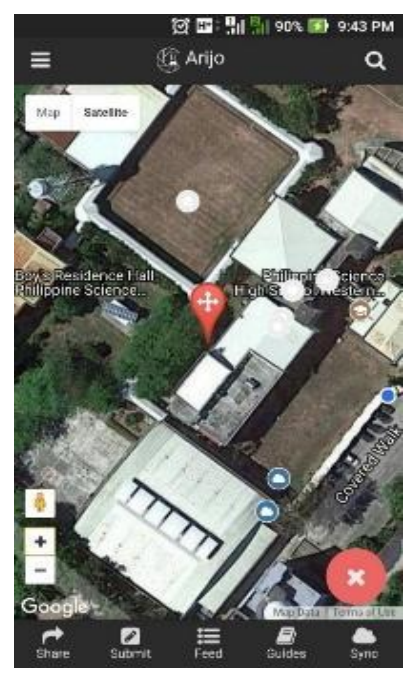

Fig. 9. Data map of Arijo.

\section{d) Phase 4 - Integrating Information Dissemination Functionality}

An encyclopedia-like section in the application was added using Appsheet's gallery tool. Each experiment's procedure was conveyed through images designed using Adobe Photoshop (see Fig. 10).

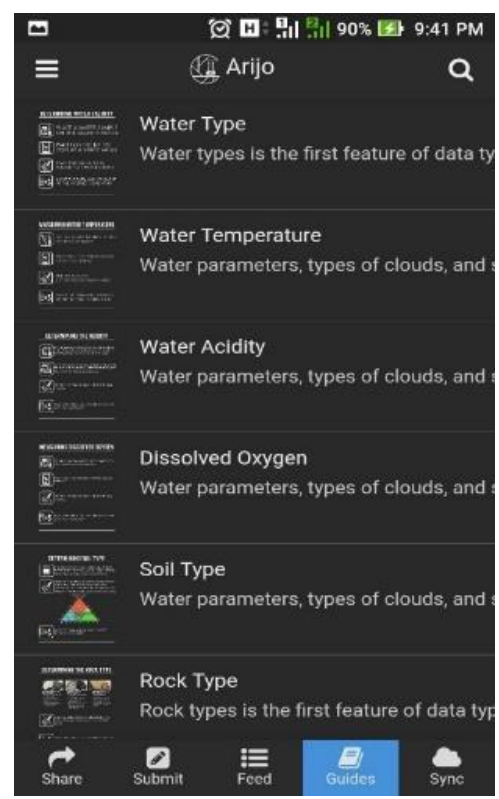

Fig. 10. Procedure selection menu.

\section{e) Phase 5 - Integrating Data Interpretation Functionality}

Data interpretation was added as Arijo's fifth phase. Every type of data in a location is shown on a page dedicated to said location. These can be selected from the application's 'data feed' page (see Fig. 11). Each page contains the location of input, name of submitter, data type and data value (see Fig. 12). Data is sourced from Arijo's Google Sheet (see Fig. 13). 


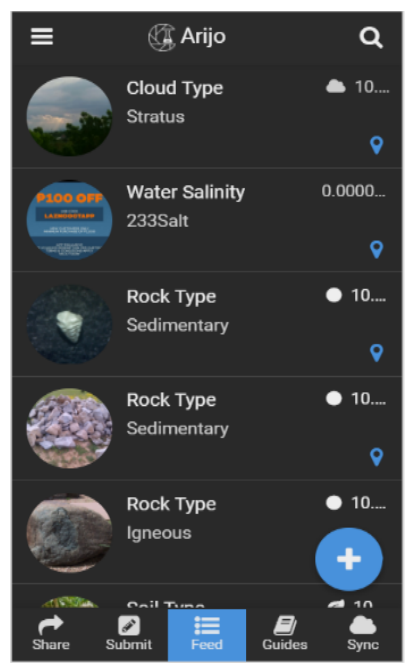

Fig. 11. Live data feed tab.

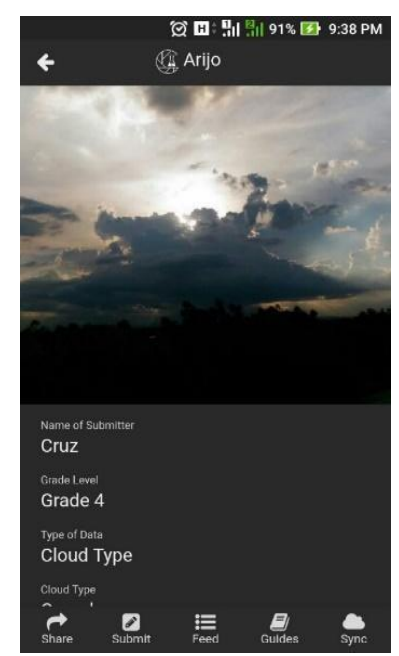

Fig. 12. Example of an interpreted data page.

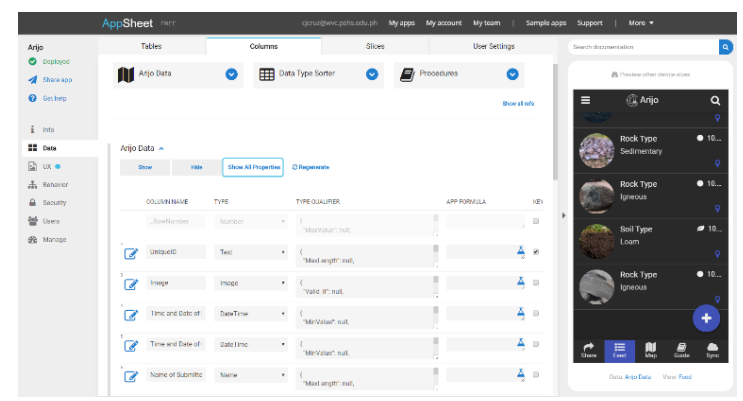

Fig. 13. Appsheet programming interface of Arijo after implementing all phases.

\section{RESULTS AND DISCUSSION}

This study aimed to develop a Location-specific Data Crowdsourcing Web Application (Arijo) using Appsheet to serve as a curriculum supplement by teaching students how to conduct experiments and making them upload their results to the internet for archival purposes.

It also aimed to design an accessible user interface for the web application, describe and record the developmental processes of the web application's data input/output, data interpretation and information dissemination functionalities, and test the web application in an open environment upon completion of development.

Using Arijo, users are able to submit data types supported by the application to a designated Google Sheet for archival purposes. Users are then able to view their submitted data as well as that of other users in a graphical form using the web application's data interpretation functionality. Data types supported by the application are based on experiments conducted in schools following the Philippine curriculum for grades three, four, and five. Users who do not know how to collect the aforementioned data types may learn to do so using the web application's information dissemination functionality.

Due to Arijo's nature as a web application, it is usable on any platform that supports the latest versions of the Microsoft Edge, Google Chrome, Apple Safari, and Mozilla Firefox web browsers. It is also installable and usable on mobile phones that run the latest versions of the Apple iOS and Google Android operating systems.

\section{1) User Interface Design}

Using the criteria defined in the review of literature, a user interface was designed. Adobe Photoshop was used to make mock-ups of the user interface; these mock-ups were then successfully implemented during the programming phase using Appsheet's built-in design tools. The interface allows users to input data, see submitted data by them or other users through the live feed or world map, and learn procedures. It also has a sync option that enables users to manually update their database should they lack internet access for an extended amount of time.

\section{2) Information Dissemination}

A section showing all the procedures needed to gather the data types that Arijo supports was programmed. Users may choose the procedure they aim to learn from the section's gallery-style selection menu. These procedures are taught through minimalistic graphics, which were designed using Adobe Photoshop and inserted into the application in the Portable Network Graphic (.png) image format. The section was programmed to be expandable should more data types be added.

\section{3) Data Flow}

Arijo collects data from user submissions and stores said data in a Google Sheet. Upon submission, pre-existing data in the Google Sheet is automatically re-sorted to accommodate the new addition. Arijo can also fetch data from the Google Sheet for data output purposes.

\section{a) Data Input/Output}

Users can input data through Arijo's form section. Multiple fields such as the value of the data, time of data gathering, location, name of the collector and other specific information will be filled up by the collector. Through Geolocation and interfacing with the phone respectively, location of data gathering and time of data submission will be filled up by the web application automatically. All submitted data are stored in the Google Sheet. 


\section{b) Data Interpretation}

Users are able to view data submitted by them and other users. In the data feed section, users can see the data in descending chronological order of submission. They may also conduct a filtered search in order to find data of specific categories.

Another way of viewing data is through the map section. On a world map parsed from Google Maps, users can view data according to where it was gathered and submitted from. Each submission is given a marker on the map; by selecting a marker, details about its corresponding submission can be seen.

\section{4) Testing}

Arijo was tested to see if it installs properly, if the data input and output functionality works as intended, and if data from the Google Sheet is displayed and interpreted properly.

\section{a) Field Test}

Arijo was tested on both Android and Apple devices. The application was also tested in a desktop computer. Sample mock data was sent to see if the data is properly uploaded and downloaded. The GPS function was in line with a user's phone's reported locations on Google Maps. Likewise, the date and time parsing was in line with the time displayed on a user's phone.

\section{B. Discussion}

Arijo had all of its aimed core functionality successfully implemented. This included:

- Data Input/Output: Allowing users to submit and store supported data types on Arijo's Google Spreadsheet through its in-app form, as well as automatically fetching where and when users submitted their data via their phone's geolocation and internal clock functionality respectively.

- Data Interpretation: Allowing users to view data submitted by them and other users in either live feed or map form.

- Information Dissemination: Teaching users how to gather the supported data types.

Area restriction code that limited the data collection to users from the Philippines was not implemented. This was because defining a specific GPS coordinate range for the Philippines is infeasible due to its archipelagic nature; an implementation of this feature would have been inaccurate at best.

Google Maps' points of interests were not removed. This is because the Appsheet API cannot filter what Google Maps feeds the application. This is not considered to be a significant problem as the points of interest may make the data points easier to locate.

Instead of the initial plan of creating an individual form for every data type, the data input forms were organized by using dropdown menus. It gave the application a compact aesthetic compared to the concept.
Only a select amount data types were included in this iteration of the web application. These were taken from the Philippine Department of Education's official curriculum. This does not limit the application's potential however, as additional data types can be added in the future.

\section{SUMMARY, CONCLUSION AND RECOMMENDATIONS}

This study aimed to develop a Location-specific Data Crowdsourcing Web Application (Arijo) to serve as a curriculum supplement by teaching students curriculum-based science experiments and giving said students a way to archive the results online in a public repository. It also aimed to document the development of the web application's various functionalities.

\section{A. Procedures}

Arijo had the following features implemented:

- Data input/output with geolocation functionality through an in-app form and Google Sheets.

- Data interpretation through the data feed and world map view.

- Information dissemination through the web application's procedures page.

\section{B. Conclusion}

The development of a Location-specific Data Crowdsourcing Web Application (Arijo) as a Curriculum Supplement is possible using a combination of Appsheet, Google Sheets, and Adobe Photoshop. All of its intended core functionalities were successfully implemented.

\section{Recommendations}

Procuring a faster and stable internet connection is essential as it is needed in order for the system to display its data regularly and effectively refresh every time new data is sent to the online document.

A more complex API is also recommended. While Appsheet is a suitable solution for medium-scale projects such as Arijo's current state, features such as increased customizability, complex animations, advanced data interpretation functionalities are not possible.

Lastly, future researchers are encouraged to think of methods to make the user interface and experience engaging. As students are the target audience, the aesthetics of applications like Arijo should cater to them.

\section{ACKNOWLEDGMENT}

We would like to thank our parents and teachers for supporting us while we developed Arijo. Specifically, we thank our advisors Eisen Ed Briones and Gerald Salazar for lending us their time and expertise for the past year and a half. We also thank the Philippine Science High School - Western Visayas Campus Research Unit, including but not limited to Dr. Aris Larroder and Jarold Mediodia, for guiding us throughout our specialization years. Lastly, we thank Serafin Farinas and Rhydd Balinas for their contributions towards the development of Arijo's prototype. 


\section{REFERENCES}

[1] Yoon SY, Dyehouse M, Lucietto AM, Diefes-Dux HA, Capobianco BM. 2014. The Effects of Integrated Science, Technology, and Engineering Education on Elementary Students Knowledge and Identity Development. School Science and Mathematics [Internet]. Available from: http://onlinelibrary.wiley.com/doi/10.1111/ssm.12090/abstract.

[2] Estonanto A. 2017. Acceptability and Difficulty of the STEM Track Implementation in Senior High School [Internet]. Available from: http://www.apjmr.com/wp-content/uploads/2017/04/APJMR2017.5.2.05.pdf.

[3] Beeland W. Jr. 2002. Student Engagement, Visual Learning and Technology: Can Interactive Whiteboards Help? [Internet]. Available from:

https://s3.amazonaws.com/academia.edu.documents/38455890/COOOO L.pdf?AWSAccessKeyId=AKIAIWOWYYGZ2Y53UL3A\&Expires $=15$ 07301802\&Signature $=$ rhnKR2sRncQfYzmDUNmnMO8FjdQ\%3D\&res ponse-content-

disposition=inline \%3B\%20filename\%3DStudent_Engagement_Visual_ Learning_and_T.pdf.

[4] Nations, D. 2015. What is a Web Application? About [Internet]. Available from: http://webtrends.about.com/od/webapplications/a/web_application.html.

[5] Christensson, P. 2016. API Definition. TechTerms. Sharpened Productions [Internet]. Available from: http://techterms.com/definition/api.

[6] Roussou M. 2004. Learning by Doing and Learning Through Play: An Exploration of Interactivity in Virtual Environments for Children [Internet]. Available from: http://nexus.hsbremerhaven.de/Library.nsf/a249ddae15ac617ac12573460029d00b/3a8 57d47de4a673bc125733e006d1061/\$FILE/p10roussou_Learn_through_Play.pdf.
[7] Davy A. n.d. Components of a smart device and smart device interactions [Internet]. Available from: http://www.mzones.org/deliverables/d234_1/papers/davy-components-of-a-smartdevice.pdf.

[8] Jazayeri M. 2007. Some Trends in Web Application Development [Internet]. Available from: https://dl.acm.org/citation.cfm?id=1254719.

[9] Kanhere SS. 2011. Participatory Sensing: Crowdsourcing Data from Mobile Smartphones in Urban Spaces. 2011 IEEE 12th International Conference on Mobile Data Management. 2011:3-6.

[10] Grove C. 2018. Introduction to the GLOBE Research Project on Leadership Worldwide [Internet]. Available from: https://www.grovewell.com/wp-content/uploads/pub-GLOBE-intro.pdf.

[11] Aanensen DM, Huntley DM, Feil EJ, Al-Own F, Spratt BG. 2009. EpiCollect: Linking Smartphones to Web Applications for Epidemiology, Ecology and Community Data Collection. PLOS ONE.

[12] Fadeyev, D. 2009. 8 Characteristics Of Successful User Interfaces [Internet]. Available from: http://usabilitypost.com/2009/04/15/8characteristics-of-successful-user-interfaces/.

[13] Department of Education. 2016. K to 12 Curriculum Guide Science [Internet]. Available from: http://www.deped.gov.ph/sites/default/files/page/2017/Science\%20CG_ with\%20tagged\%20sci\%20equipment_revised.pdf.

[14] Environment Guide. 2015. Freshwater Bodies. [Internet]. Available from: http://www.environmentguide.org.nz/issues/freshwater/thefreshwater-environment/.

[15] Perlman, H. 2014. Water Properties and Measurements. USGS Water Science School. Available from: http://water.usgs.gov/edu/characteristics.html.

[16] Dissolved Oxygen. 2016. Environmental Measurement Systems. [Internet]. Available from: http://www.fondriest.com/environmentalmeasurements/parameters/water-quality/dissolved-oxygen 